DOI 10.37882/2223-2982.2020.07-2.18

\title{
ДИДАКТИЧЕСКИЕ АСПЕКТЫ ПРОЕКТИРОВАНИЯ НА УРОКАХ ЛИТЕРАТУРЫ НА УРОВНЕ ОСНОВНОГО ОБЩЕГО ОБРАЗОВАНИЯ
}

\section{DIDACTIC ASPECTS OF DESIGNING IN LITERATURE LESSONS AT THE LEVEL OF BASIC GENERAL EDUCATION}

Li Ruomei

Summary: The Author studies the forms of project work and the possibilities of their practical application in the classroom. The purpose of the study is to justify the feasibility of using the project method in literature lessons in high school. The scientific novelty consists in demonstrating the advantages of using the project method on the example of studying different sections of the school literature course. The results of the study showed that project activity is a method that contributes to the formation of key competencies of students, as well as providing not only the consolidation and activation of the passed material, but also stimulating the development of creative abilities of students.

Keywords: projection, project method, literature lessons, Russian literature, creative approach, teaching methods, secondary school.
J лавной задачей российской образовательной политики является модернизация учебного процесса. K эффективным методам современного обучения данным стандартом отнесены методы организации проектной и исследовательской деятельности школьников, которые позволяют формировать умения самостоятельно добывать новые знания, работать с информацией, формулировать выводы, а также строить умозаключения.

Ориентация на данный вид деятельности включена в программы всех школьных предметов. Педагогическую целесообразность применения проектных технологий подчеркивает создание такого вида деятельности, который направлен на формирование культуры умственного труда учеников. Образовательный стандарт предъявляет к учителю требования самостоятельно овладеть методикой проектов, а также обучить такой методике своих учеников.

Таким образом, актуальность предлагаемой работы обусловлена необходимостью в соответствии с целью модернизации учебного процесса задействовать в обучении эффективные современные методы, одним из которых, в частности, является метод проектов, который способствует росту качества образовательного процес-
Ли Жомэй,

преподаватель, дочент, Шаньдунский гидротехнический институт, пр. Шаньдунь, г. Жичжао, Китай

47374351@q9.com

Аннотация: Автор изучает формы проектной работы и возможности их практического применения на уроках. Целью исследования является обоснование целесообразности применения метода проектов на уроках литературы В средней школе. Научная новизна заключается в демонстрации преимуществ использования проектного метода на примере изучения разных разделов школьного курса литературы. Результаты исследования показали, что проектная деятельность является методом, способствующим формированию ключевых компетенций учеников, а также обеспечивающим не только закрепление и активизацию пройденного материала, но и стимулирующим развитие творческих способностей обучающихся.

Ключевые слова: проектирование, метод проектов, уроки литературы, русская литература, творческий подход, методы обучения, средняя школа.

са и эффективному развитию компетенций учителя и учащихся.

В соответствии с целью обоснования целесообразности применения метода проектов на уроках литературы предполагалось решение следующих задач: 1) проанализировать различные подходы к трактовке метода проектов; 2) рассмотреть возможные формы проектов, а также этапы реализации метода проектов на уроках; 3) на основе анализа теоретических аспектов сделать вывод о том, на каком этапе изучения темы наиболее целесообразно использовать метод проектов; 4) разграничить роли учителя и учеников в процессе выполнения проектной работы; 5) показать преимущества использования метода проектов на конкретных примерах изучения разных разделов курса литературы в школе, а также предложить возможные результаты проектной деятельности в рамках данных разделов.

В соответствии с характером поставленных задач в работе были использованы следующие методы исследования: анализ научной и методической литературы, индуктивный и дедуктивный методы для формулировки выводов. 
Теоретической базой исследования являются теоретические положения, изложенные в учебно-методическом пособии М.А. Ступницкой и в работах Е.С. Полат, посвящённых использованию современных технологий в образовании, анализ современных образовательных технологий Г.К. Селевко. Материалом для исследования выступили также методические разработки и статьи учителей-практиков, в частности, И.А. Беловой и И.А. Ральниковой, в которых описаны конкретные результаты апробации метода проектов в школе на уроках литературы.

Практическая значимость статьи состоит в том, что её результаты, материалы и общие выводы могут быть использованы в работе учителей-практиков на уроках литературы, а также при подготовке к выступлениям на конференциях в рамках темы исследования.

Проект в широком понимании - это замысел (например, архитектурный проект здания), однако проектом выступает и сама последовательность шагов от замысла к реализации, которая завершается получением некоторого продукта. Исследователь К.Н. Поливанова для разграничения понятий считает, что проектом можно именовать весь путь от идеи до получения продукта, а воплощенная в любых формах идея или замысел - это эскиз $[10$, с. 61$]$.

Также имеется мнение, что проект является целенаправленным управляемым изменением, фиксированным во времени [7, с.17]. Как считает М.А. Ступницкая [7], проект - это работа, призванная решить определенную проблему при помощи самого оптимального способа.

Сущность проектного метода обучения раскрыта в работах В. В. Гузеева [2, с.109]. Данный автор определяет, что именно метод проектов позволяет в полном объеме реализовать проблемное обучение. Структура проектной деятельности, по В.В. Гузееву, такова: учителю нужно занять позицию руководителя учебной группы, определив для детей необходимые результаты, а также поставив цель работы. Внутри проектной деятельности ученики должны быть максимально самостоятельны: они определяют этапные задачи, выявляют алгоритм их решения, а также производят коррекцию собственной деятельности.

Другим автором, Г.К. Селевко, проект позиционируется как составляющая часть учебного процесса. Исследователь приходит к выводу, что метод проектов может быть:

- вариантом технологии проблемного обучения;

- комплексным обучающим методом, дающим возможность создать условия для индивидуального обучения и позволяющим ученику развить навыки самостоятельной работы в таких видах дея- тельности, как планирование, организация и контроль;

- способом группового обучения;

- способом организации творческой деятельности учеников [6, с. 32].

И.Д. Чечель считает, что исследовательский проект, который является формой научного творчества учеников, должен занять значимую позицию среди современных педагогических технологий. По мнению исследователя, цель данной технологии в процессе обучения - освоение новых способов человеческой деятельности в обществе, путём использования уже имеющихся знаний и приобретения новых в рамках реализации проектного задания[9, с. 8].

Теоретическую основу метода проектов разрабатывала в своих трудах Е.С. Полат [4, с. 25]. Так, по ее мнению, метод проектов выступает способом достижения дидактической цели посредством детальной разработки, результат которой должен носить практический характер и быть обязательно оформленным. Чтобы получить указанный результат, учеников нужно научить самостоятельному мышлению, поиску различных способов решения проблемы, применять знания из разных областей, сформировать у них умения строить прогнозы своей деятельности.

Рассмотрим основные виды проектов, используемых педагогом в современной школе.

В зависимости от доминирующей деятельности можно выделить следующие типы проектов:

1. Исследовательские проекты.

Здесь ученикам необходимо актуализировать тему, определить ряд этапных задач, выдвинуть гипотезу и проверить ее, а также обсудить результаты, полученные в ходе работы. В данном виде проекта могут быть использованы такие методы, как социологический опрос, моделирование, лабораторный эксперимент.

2. Информационные проекты.

В рамках таких проектов отбирается информация, описывающая или характеризующая какойто объект, затем такая информация подвергается анализу и выносится на обсуждение. Подобные проекты публикуются в печати или в сети Интернет.

3. Творческие проекты.

Здесь возможно применение нетрадиционного подхода к оформлению результатов. Ведущими методами здесь могут выступать театрализация, изучение произведений различных видов искусств и пр.

4. Ролевые проекты.

Роли распределяются между участниками проек- 
та, причем персонажи, которых они представляют, могут быть как реальными, так и придуманными. К результату проекта его участники приходят только в финале проекта.

5. Практико-ориентированные проекты. Целями данного проекта выступают социальные интересы самих участников проекта или внешнего заказчика.

Также, в соответствии с предметно-содержательной областью выделяют:

- монопроекты в рамках одной области знаний;

- межпредметные проекты на стыке различных областей. быть:

В соответствии с координацией проекта они могут

- с открытой координацией (жесткий);

- с закрытой координацией (гибкий).

В соответствии с количеством участников проекты могут быть:

- индивидуальными;

- парными;

- групповыми.

Исследуя различные подходы к понятию метода проектов, можно заключить, что позиции авторов совпадают в следующем: все они считают проект инновационным способом организации обучения, а также способом организации самостоятельной деятельности учеников.

Технология организации проектной деятельности состоит из:

1. характеристики этапов работы над проектом;

2. матрицы согласования этапов технологии и уУД для основной школы;

3. методических рекомендаций к проекту [10, с. 72].

Среди этапов проекта нужно обозначить:

- подготовительный, включающий подготовку проектного задания, на котором изучают общественное мнение, ставят и формулируют проблему, определяют причины ее существования, конкретизируют цели и задачи проекта, а также выявляют социальный аспект проекта;

- технологический, на котором разрабатывается план самостоятельной проектной деятельности, уточняется его содержание, расписываются роли и действия среди участников проектной деятельности, выявляются возможности и места получения информации, устанавливается система оценки, а также то, каким способом будут получены результаты;

- завершающий, на котором представляется презентация проекта и проводится его экспертиза, в также осуществляется самооценка и рефлексия результатов [3, с. 41].

Проектная деятельность является достаточно трудоемкой. Почему педагоги предпочитают применять в своей деятельности проектный метод? Скорее всего, причина заключается в том, что на уроках литературы у школьников развивается самостоятельность, творческая активность. Используя данный метод, педагог позиционирует учеников уже как субъект учебной деятельности, при этом, сам он выступает как консультант. Данная форма контроля имеет ряд преимуществ, так как дает возможность потенцировать учебный интерес детей и работу их мысли.

Проектная работа также предполагает возложение ответственности на самого ученика.

Целесообразно вводить в учебный процесс проектную деятельность после того, как тема уже была изучена. Речь идет о творческом уровне обучения, перед которым проводится значительная, кропотливая работа, связанная с закреплением и активизацией материала на репродуктивном этапе.

Литература в школе - это предмет, предполагающий на протяжении всего ее изучения раскрыть перед учащимися мир книги, обучить последних глубокому анализу творческого произведения, развивать у них эстетический подход. Исторический и хронологический подход к изучению литературы в рамках определенных тем дает возможность ученикам представить себе развитие литературного творчества в качестве процесса.

Кроме того, применение метода проекта на уроках литературы дает возможность развивать навыки практического подхода к изучению литературных произведений. Для повышения интереса учеников к проектной деятельности учителя литературы используют ряд игровых, творческих и исследовательских методов.

Повышение мотивации к обучению на уроках, где используется проектный метод обучения, предполагается за счет внедрения бесед, дискуссий, творческих заданий. Именно литература представляет собой благодатную почву для внедрения обучения с помощью разработки и реализации проектов. Данный проектный метод позволяет также повысить уровень читательского интереса учеников, а также расширить их читательский кругозор. Дети-участники проекта, как правило, начинают испытывать желание изучить нечто новое и интересное, повышают объем своих знаний и стараются добыть их самостоятельно.

Результатом проекта выступает развитие у учащихся умений координировать свои действия в групповой 
работе, определить недостаток знаний и пути их пополнения. Также дети учатся быстро решать проблему, учитывая мнение участников обсуждения, прислушиваться к оппонентам и формулировать грамотный ответ на возражения. Интересно построенная работа в группах дает ученикам возможность ощутить всю глубину предмета, расширить свой кругозор. Учитель же, в свою очередь, сможет повысить качество знаний учеников и обозначить перспективы дальнейшего обучения литературе с учетом нового уровня развития своих учащихся.

Соответственно, проектную деятельность можно считать перспективным способом обучения в современной школе, который дает возможность масштабно использовать информационные технологии на уроках, а также стимулировать самостоятельную работу учеников и обеспечить личностно-ориентированный подход в обучении. Однако важно, чтобы учитель грамотно вводил проектные методы в стандартную структуру обучения литературе.

Применение метода проекта возможно уже на уроках в пятом классе, так как творческое развитие учеников данного возраста достаточно высоко. Дети стремятся к совместной творческой работе, и в результате продуктами их деятельности могу стать стенгазеты, видеофильмы, а также сценарии праздников и пр.

Ученики с интересом идут на уроки, форма которых необычна, их интерес позволяет учителю эффективно решить ряд сложных образовательных задач. В частности, проектный метод позволяет учителю дать ученикам пятого класса навыки работы с текстом: выявлять его жанровые особенности, структурировать произведение, анализировать эпизоды и пр. Эта задача с успехом может быть решена, если в урок будет введено задание, предполагающее создание комиксов. Для выполнения такого задания дети должны на основе чтения текста создать рисунки, которые могут продемонстрировать характер персонажей. Наибольший эффект такая работа принесет в группе, где дети самостоятельно распределяют свои роли.

Если речь идет об уроках в классах старше пятого, то дети должны получать задания сложнее. Например, в 7 классе ученики должны не только самостоятельно изучить произведение, но и рассмотреть его в контексте эпохи.

Когда изучаются обзорные темы, такие как, например, «Духовная литература», использование метода проектов целесообразно, так как это достаточно трудный раздел литературного курса. Данные темы позволяют ученикам получить знания о крупных явлениях отечественной литературы и сформировать собственное отношение к развитию литературного процесса.
Изучая раздел «Духовная литература», учащиеся могут получить задание написать сценарий лекции для посетителей библиотеки по «Житию Сергия Радонежского» Епифания Премудрого. Основой проекта выступает ролевая игра, где дети выступают «историками», «литературоведами», «искусствоведами». Ученикам нужно самостоятельно найти исторические сведения об эпохе, в которую жил Сергий, прокомментировать текст, поработать над музыкальным и художественным оформлением, выбрать отрывки для выразительного чтения.

Творчество в проектной деятельности может быть реализовано и индивидуально. Традиционным сочинениям на литературную тему можно придать практическую направленность. Например, это может быть написание статей для хрестоматий или литературных альманахов. Серьезность поставленного задания определяет высокий уровень мотивации учеников [3, с. 46].

В большинстве случаев результатом всей учебной деятельности учеников на уроке литературы выступает итоговое сочинение, подготовку к которому они осуществляют на каждом уроке, описывая различные предметы, обучаясь аргументировать и подтверждать свою точку зрения, определяя тему, проблему, антитезу и пр. Очень многим детям работа над сочинением дается нелегко. Чтобы они могли научиться грамотно работать над сочинением, учитель может в течение всего обучения литературе использовать парный метод работы. Именно обсуждая проблемы раскрытия темы во время работы друг с другом, дети могут успешно составить план работы, подобрать аргументы, поработать с критической литературой и пр.

Данный вид проектной деятельности даст возможность детям увидеть, что на одну проблему может быть несколько точек зрения, а также научит их формулировать аргументы, чтобы отстоять собственную позицию или принять позицию оппонента. Здесь может иметь место применение ролевых проектов, где дети играют ту или иную роль. При этом, каждый из участников такого проекта может занять позицию другого и играть уже противоположную роль, используя уже собственные аргументы. [3, с. 49].

Подобные уроки-проекты достаточно зрелищны. В частности, итоговая читательская конференция в 8-ом классе может проводиться в форме «литературной гостиной», где встречаются представители разных эпох и литературных направлений.

Также в процессе выполнения исследовательских проектов ученики могут научиться работать с различными источниками. Это научные мини-исследования, которые предполагают актуализацию темы, позволяют определить проблему, сформулировать гипотезу, провести 
ее всестороннее обсуждение и формирование выводов. Такие проекты можно осуществлять уже в 7-ом классе, когда ученики приобретают достаточный читательский опыт. Так, при изучении раздела «Героический эпос» на финальном занятии можно предложить детям реализовать исследовательский культурологический проект: «Общее и различное в жизненном укладе скандинавов и древних славян». Данный проект поможет детям осознать единство мировой литературы.

Еще один вид проектов - прикладные. Они способствуют развитию умения координировать свои действия, соотносить их с определенной целью, осуществлять отбор самого существенного, необходимого для работы. Подобные проекты чаще всего имеют социальную направленность и обладают практическим характером [3, с. 51]. Учащиеся самостоятельно разрабатывают памятки, словарные статьи, справочные материалы и пр. Работу должна отличать новизна (субъективная или объективная) и научная или практическая ценность. Соответственно, структура таких проектов должна быть продуманной, а каждый этап работы должен быть вынесен на коллективное обсуждение. Так, если планируется провести урок-семинар, то ученикам необходимо разработать вопросник к нему, составить список литературы.

По причине ориентированности ФГОС на системнодеятельностный подход в обучении необходимы новые средства его реализации, среди которых проектирование позиционируется в качестве ведущей деятельности, формирующей умения самостоятельно получать новые знания, организовывать работу с информацией, формулировать выводы и умозаключения [8].

Новые педагогические технологии позволяют повысить ответственность ученика за процесс обучения, дают ему возможность почувствовать себя в качестве равноправного участника совместной с учителем деятельности.

За счет обращения к проектной методике в образовательном процессе можно организовать учет индивидуальных особенностей развития школьников, а также прочнее закрепить полученный на уроках материал.

Проектную деятельность в форме, доступной для учеников, можно использовать на любом уровне и в любом возрасте. Ребенок, который самостоятельно обдумывает и отбирает нужную информацию, закрепляет необходимый материал.

Учащиеся погружаются в проектную деятельность постепенно, и уже к старшим классам они должны овладеть методикой планирования, а также предвидеть результаты проекта. Целью технологии проектной работы выступает развитие культуры умственного труда учащегося, который должен быть критичным, рефлексирующим, стремиться самовыразиться и реализовать внутреннее «Я». Соответственно, за счет проектной технологии обеспечивается улучшение качества образования школьников, что повышает востребованность выпускников на рынке труда, их успешность в жизни, позволяет адаптироваться в динамичном социуме. Заслугой метода проектов можно считать то, что он способствует созданию ситуации успеха для всех учеников, без учета их способностей и личностных особенностей развития.

Практика учителей литературы демонстрирует, что применение метода проектов достаточно эффективно, так как он стимулирует интерес учеников к изучению предмета, развивает у них навыки самостоятельной, поисковой и творческой деятельности и, таким образом, способствует повышению качества знаний учащихся [1] $[5]$.

\section{Выводы}

В результате всестороннего анализа метода проектов, являющегося инновационным способом организации обучения, подтверждён тот факт, что его использование на уроках литературы в средней школе является целесообразным, так как способствует реализации системно-деятельностного подхода в обучении, на который ориентирован ФГОС. Накапливая опыт использования проектного метода при изучении литературы, ученики смогут развить в себе все ключевые компетенции школьника (коммуникативную, культуроведческую, информационную, языковую, исследовательскую), что даст им возможность не только успешно сдать выпускные экзамены, но и стать востребованными специалистами и занять достойное место в обществе.

Конечно, в той или иной форме проектную деятельность можно использовать на любом уровне обучения и в любом возрасте, но начинать использование метода проектов на уроках литературы представляется наиболее целесообразным в пятом классе, так как к этому возрасту уровень развития творческих способностей обучающихся уже достаточно высок.

Наибольший эффект проектная деятельность приносит в группе, где дети самостоятельно распределяют свои роли, при этом учитель выступает только в роли консультанта, а субъектом учебной деятельности позиционируется ученик.

В статье были описаны возможности применения метода проектов на примере изучения конкретных разделов школьного курса литературы, в частности раздела «Духовная литература». Дальнейшие исследования в рамках темы предполагается проводить именно в на- 
правлении анализа эффективности использования различных типов проектов с учётом изменяющихся возрастных психологических особенностей учеников разных классов, а также в направлении описания возможных форм и результатов проектной работы при изучении тех или иных разделов курса литературы.

\section{ЛИТЕРАТУРА}

1. Белова И.А. Методическая разработка на тему «Проектная деятельность учащихся на уроке литературы» [Электронный pecypc]. URL: https://gigabaza.ru/ doc/97777-p2.html (дата обращения: 12.05.2020).

2. Гузеев В.В. Планирование результатов образования и образовательная технология. М.: Народное образование, 2000. 206 с.

3. Полат Е.С. Новые педагогические и информационные технологии в системе образования: учебное пособие для студентов педагогических вузов и систем повышения квалификации педагогических кадров. М. : Академия, 2000. 275 с.

4. Полат Е.С. Современные педагогические и информационные технологии в системе образования: учебное пособие для студентов высших учебных заведений. 3-е изд., стер. М.: Издательский центр «Академия», 2010. 368с.

5. Ральникова И.А. Использование метода проектов на уроках литературы как способ формирования ключевых компетентностей [Электронный ресурс]. URL: https://nsportal.ru/shkola/obshchepedagogicheskie-tekhnologii/library/2011/10/30/metod-proektov-na-urokakh-literatury-i (дата обращения: 12.05.2020).

6. Селевко Г.К. Энциклопедия образовательных технологий. В 2-х т. / Г.К. Селевко. Т. 1. М.: Народное образование, 2005. 556 с.

7. Ступницкая М.А. Что такое учебный проект? М.: Первое сентября, 2010. 45 с.

8. ФГОС 000. Министерство образования и науки РФ [Электронный ресурс]. URL: http://минобрнауки.рф /документы/543 (дата обращения 11 февраля 2020 г.).

9. Чечель И.Д. Метод проектов: субъективная и объективная оценка результатов // Директор школы. 1998. №4. С.7-12.

10. Яковлева Н.Ф. Проектная деятельность в образовательном учреждении: учеб. пособие. 2-е изд., стер. М.:ФЛИНТА, 2014. 144 с.

$$
\text { ๑ Ли Жомэй (47374351@qq.com). }
$$

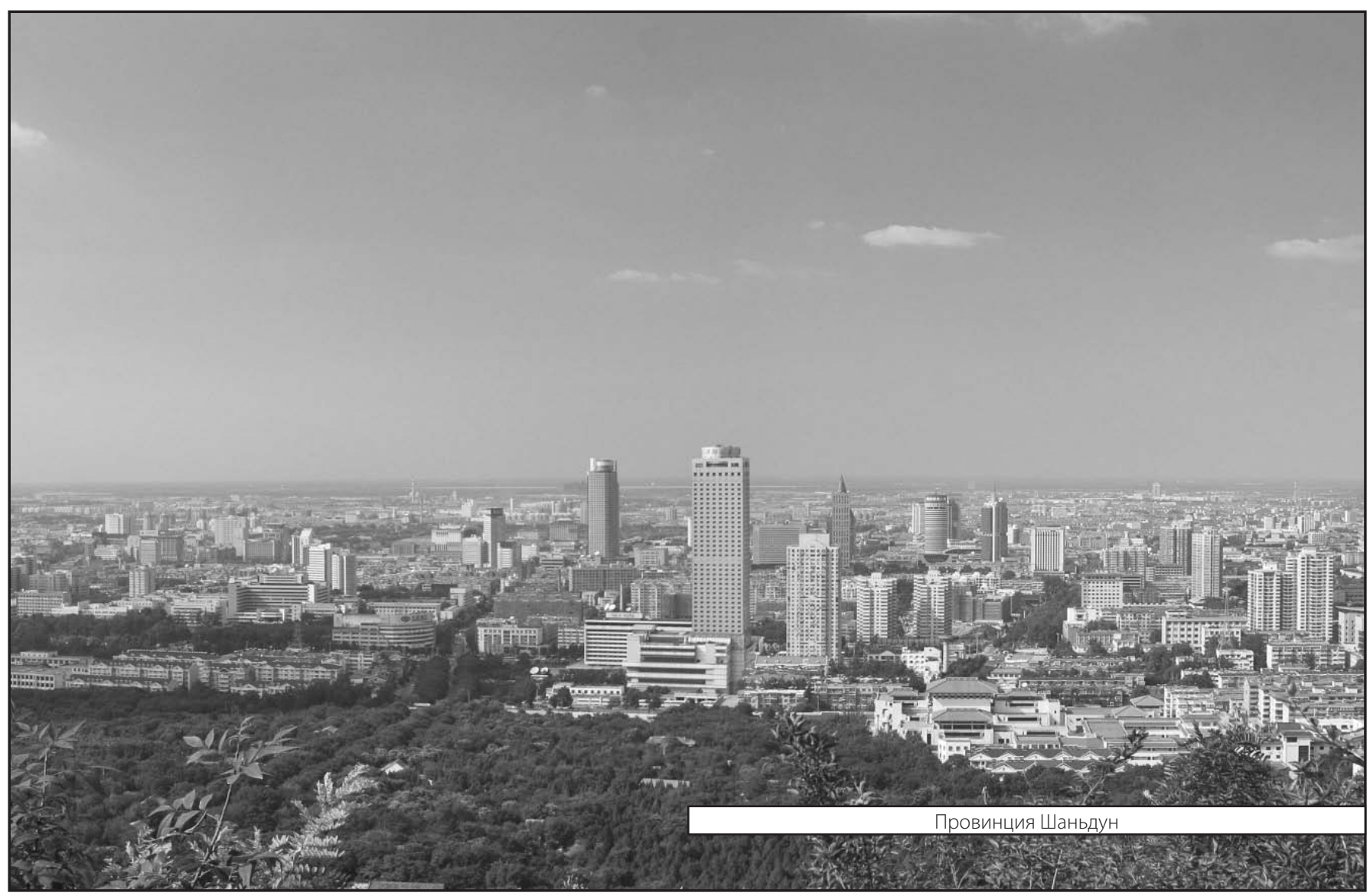

